\title{
Em defesa da paródia ${ }^{1}$
}

10.11606/2316-9877.2021.v9i2.193334

\section{Francisco Blanco ${ }^{2}$}

La Habana, Cuba

A polêmica na imprensa é um aspecto que não se deve evitar, sempre que dela se desprenda o esclarecimento oportuno do assunto tratado. É o leitor, em definitivo, que agradece quando lhe oferecem distintos ângulos do problema, e desta maneira pode tirar suas próprias conclusões. Lamentavelmente, às vezes só se recebe o silêncio por resposta.

O anteriormente exposto vem a propósito de um artigo publicado nesta própria revista [Mujeres] em sua edição de dezembro, sob o título de "O respeito ao direito alheio", no qual sua autora, entre outras coisas, diz: "Parece já um hábito a ponto de criar raízes, o fenômeno de utilizar argumentos da obra de um artista e criar, entre aspas, outra".

\footnotetext{
${ }^{1}$ Texto publicado na revista Mujeres, em 1989, em resposta a um artigo da jornalista Margarita Carmona, de dezembro de 1988. Tradução, adaptação e acréscimo de figuras: Waldomiro Vergueiro.

${ }^{2}$ Francisco Pascacio Blanco Ávila (Blanquito) foi um quadrinista cubano de grande produção artística e intelectual. Nascido em 1930 na cidade de La Habana, Cuba, faleceu na mesma cidade em abril de 2021, aos 90 anos. Graduou-se em 1958 na Escola Profesional de Periodismo Manuel Márquez Sterling. Publicou seu primeiro desenho na revista Fotos, em 1948. Trabalhou como caricaturista no periódico El Mundo, do qual passou para a agência Prensa Latina. Foi fundador da revista Palante, publicação humorística que dirigiu durante 15 anos. Ali alcançou grande popularidade com suas histórias em quadrinhos, dentre os quais se destaca a série $A y$, Vecino. Suas caricaturas apareceam em boa parte dos meios oficiais da ilha de Cuba, como os jornais Trabajadores, Granma, Juventud Rebelde y Tribuna de La Habana. Fundou e editou as revistas em quadrinhos Cómicos, LPV, Pablo, La Calle e Mi Barrio, e criou título como Matilda y sus amigos, Pol Brix contra el ladrón invisible, Los siete samuráis del 70 e Trucutuerca y Trescabitos. Recibeu em 2018 o Premio Nacional de Periodismo José Martí, além da Distinción por la Cultura Nacional e dezenas de reconhecimentos internacionais. Pensador e polemista apaixonado, defensor incansável das histórias em quadrinhos, ministrou conferências e escreveu vários artigos sobre o tema, que publicou em jornais e revistas em seu país e no exterior. Esteve no Brasil no início da década de 1990, quando da Primeira Bienal Internacional de Histórias em Quadrinhos, acompanhando uma exposição de quadrinhos cubanos. Amostras de suas produções artísticas podem ser encontradas no endereço: http://ayvecino.blogspot.com/2017/04/tira-comica-ay-vecino.html.
} 
Parece que a colega desconhece uma grande parte da obra dos clássicos, pois, desde épocas remotas, gregos e romanos já exploravam dois tipos de paródias: as heroico-cômicas e a dramática. Nelas se distinguiram trágico como Eurípedes e até ao famosíssimo Homero é atribuída a Batracomiomaquia (figura 1), essa deliciosa guerra entre sapos e ratos.

Que foi Don Quijote de La Mancha (figura 2), obra-prima da literatura espanhola, senão a grande paródia de toda novela de cavalaria escrita até então? E que foram La Gatomaquía (figura 3), de Lope de Vega; La Masquea de Villaviciosa e La Asneida, de Cosme de Aldana?

Figuras 1, 2 e 3 - Algumas obras paródicas da literatura clássica
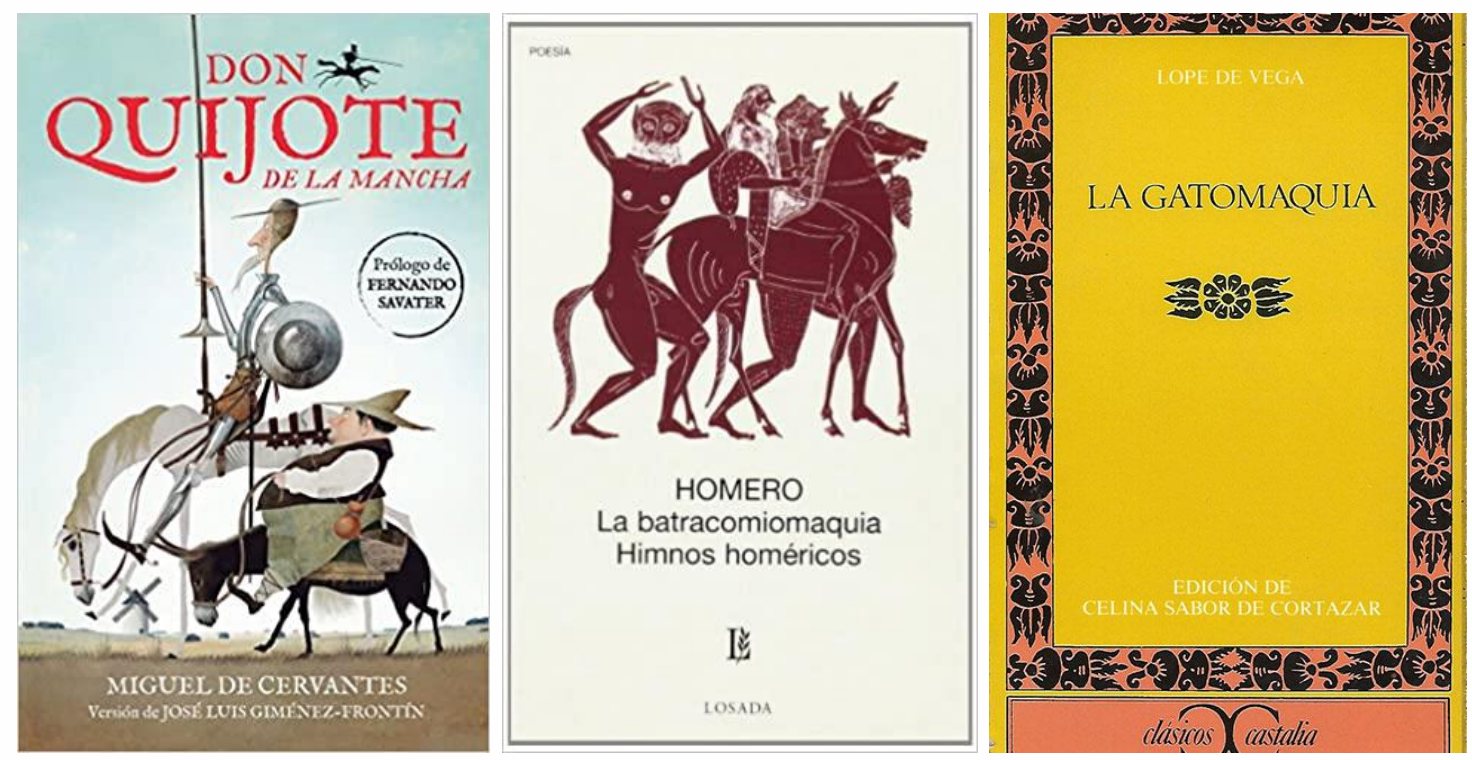

Fonte: Imagens disponíveis na internet

Mais ainda, cheguemos mais próximos no tempo e recordemos as três versões cinematográficas de Cantinflas em Romeu e Julieta (1943, figura 4), Os três mosqueteiros (1942) e Nem sangue e nem areia (1941, figura 5). E sem nos levantarmos da cadeira, deleitemo-nos de novo com essa de montagem que foi Cliente morto não paga (1982, figura 6), película-colagem de Steve Martin, que utilizou fragmentos de fitas famosas de Burt Lancaster, Humphrey Bogart, Lana Turner, Bete Davis, Alan Ladd e Joan Crawford, dentre outras muitas estrelas de Hollywood dos anos quarenta, para convertê-las em uma incrível comédia de intrigas. 
Figuras 4, 5 e 6 - Paródias cinematográficas

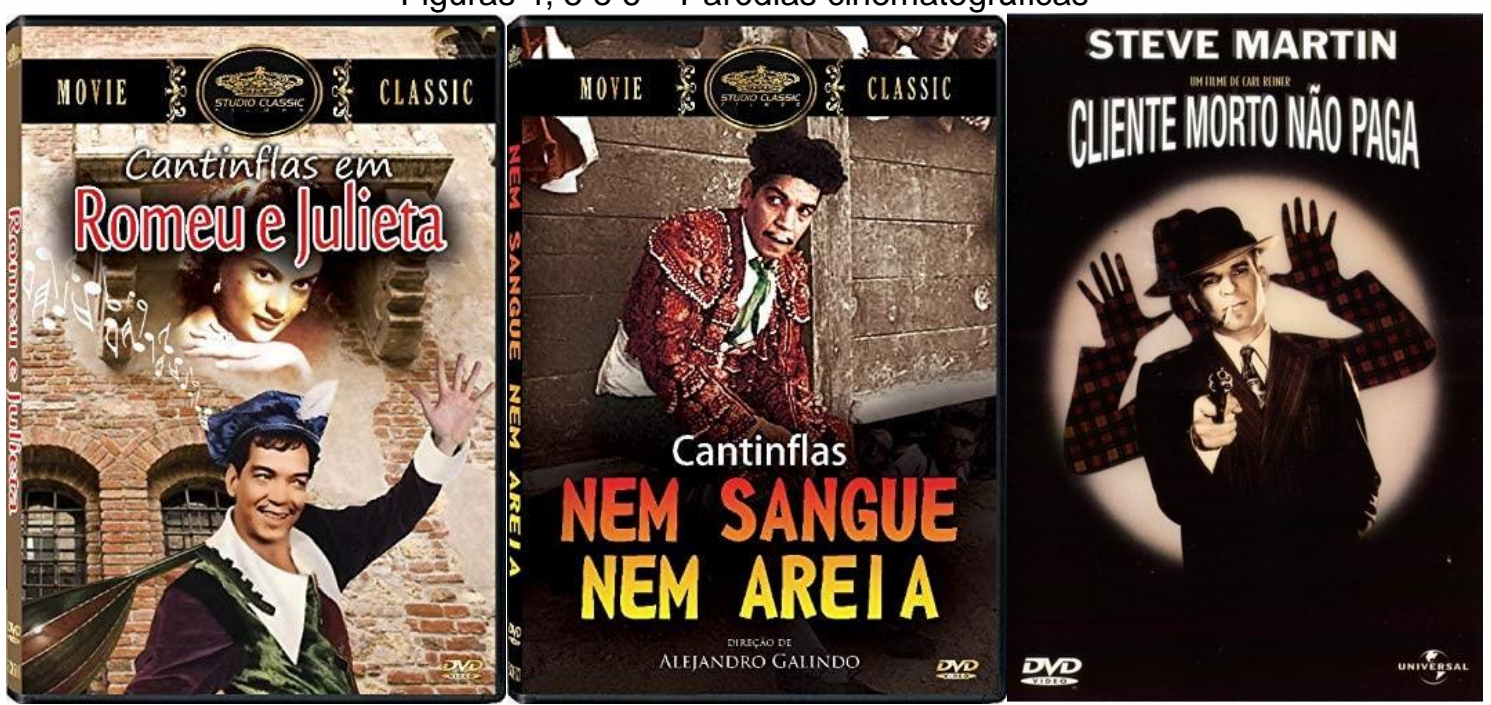

Fonte: Imagens disponíveis na internet

Poderíamos apresentar milhares de bons exemplos paródicos para demonstrar que ocorrem em todo o mundo e não somente na televisão ou na história em quadrinhos, mas também na literatura, no teatro e até na escultura. Portanto, é generalizar demais atribuir a nossos criadores a tendência de parodiar somente obras estrangeiras (figura 7). Na atualidade, é quase impossível selecionar um artista que não se tenha inspirado ou apoderado de uma obra anterior para recriá-la. Inclusive, pode chegar-se a extremos como Harold Bloom, que sugere que "toda obra de arte é uma imitação ou um malentendido de outra procedente". Umberto Eco aborda igualmente a originalidade quando dá como válida a cópia artística e põe como exemplo a que faziam as oficinas de artesões do Renacimento e a do pintor pop sobre uma garrafa de coca-cola. O destacado ensaísta remata dizendo: "Se não existe muita paixão e habilidade artesanal, tais exercícios podem aproximar-se da paródia, que quando é voluntária, é uma forma de arte e quando é involuntária, é uma desgraça"... (ECO, 1988). 
Figura 7 - Exemplo de que em Cuba não se parodiam somente obras estrangeiras
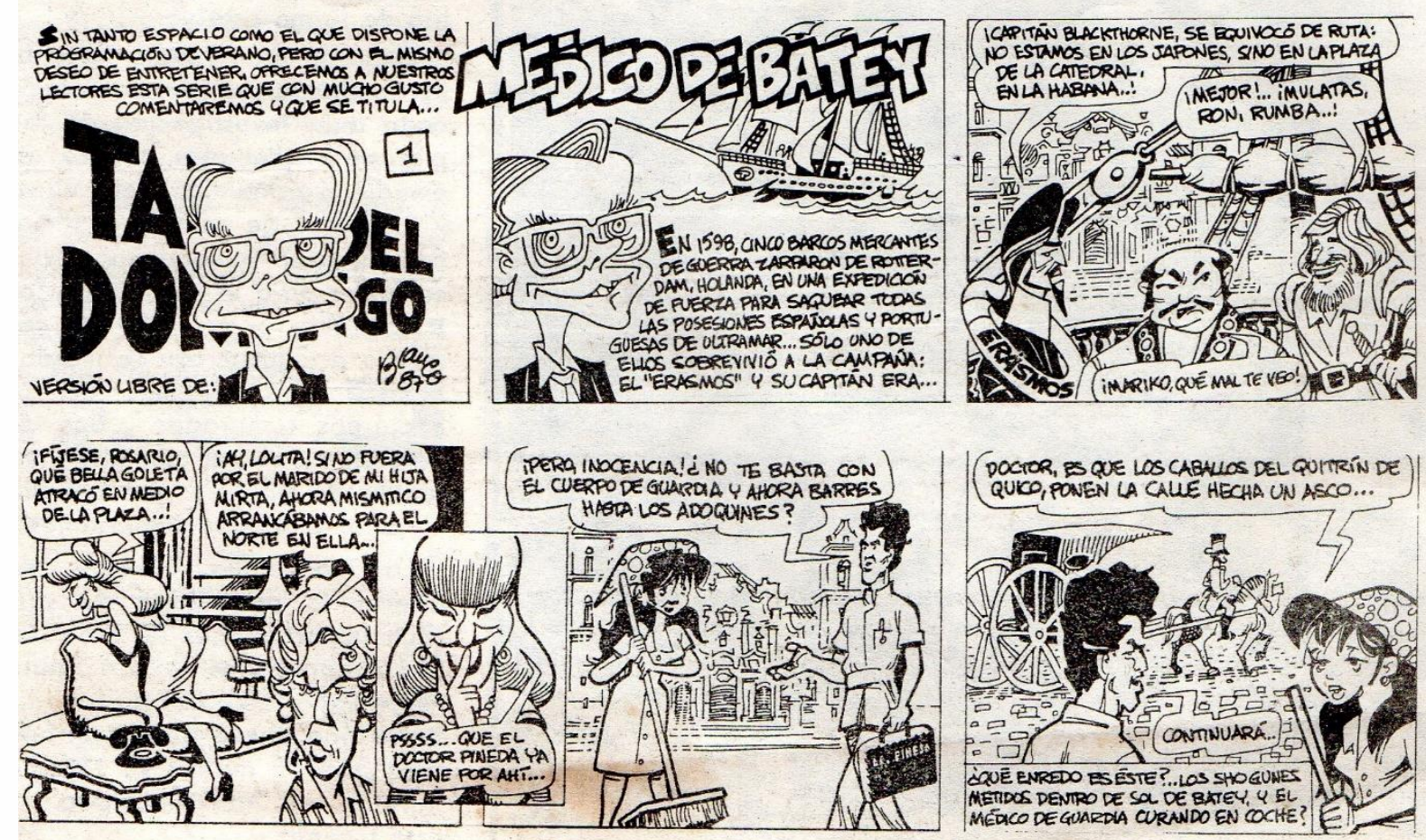

Fonte: Blanco, Francisco. Juventud Rebelde, 1987.

Não é necessário diferenciar entre a intencionalidade da paródia e essas versões que, pretendendo "ser sérias" se convertem em algo risível e das quais não se trata neste trabalho. A estes se poderia qualificar de facilismo, para usar as próprias palavras da colega, que em seguida enfoca a obra de Alejandro García (Virulo) e sua versão satírica de El Arabe y la Esclava, ao mesmo tempo em que felicita o Conjunto Nacional de Espectáculos por abandonar essa linha. "Agora preparam e oferecem pratos originais (grifo nosso) sm necessidade de apropriar-se das ideias, boas, regulares ou más de outro autor. Isto se chama ética profissional".

$\mathrm{Na}$ realidade não se pode crer que o jovem e talentoso criador cubano renuncie à utilização de um gênero como a paródia, que é consubstancial ao próprio teatro, e que combina muito bem com Virulo e a seu estilo personalíssimo de fazer humor. Quanto à ética, tampouco creio que as adaptações humorísticas, seus códigos e licenças tenham algo a ver com essa parte da filosofia que trata sobre a moral e as obrigações dos homens.

Marmontel, autor francês del século XVI, dizia: "São a exatitude das relações, a própria, a natural, a verossimilitude, a que constitui o sal, a graça e a firmeza da paródia" (SAINS DE ROBLES, 1972). O que responde à crítica da 
companheira Margarita Carmona quando esta se refere ao trabalho gráfico desenvolvido pela colega Juventud Rebelde sobre a história em quadrinhos paródia da telenovela Doña Beija.

Como aqui se faz uma alusão à minha obra, ainda que não se mencione, posso assegurar que o adiantado da série brasileira foi totalmente intencional e não precisamente com o ânimo de prejudicar ao telespectador, mas sim de recriar situações já vistas. O melhor exemplo é a própria ilustração em que se apoia do trabalho anterior da revista Mujeres, no qual aparece Maria Sampaio tratando de se envenenar quando toma conhecimento de que Bella vai ter um filho bastardo de Antonio, enquanto que na versão televisiva, ela dá um tiro em si mesma (figura 8).

Figura 8 - Último capítulo da história em quadrinhos publicada por Juventud Rebelde entre julho e setembro de 1988

\section{Doña Bella}

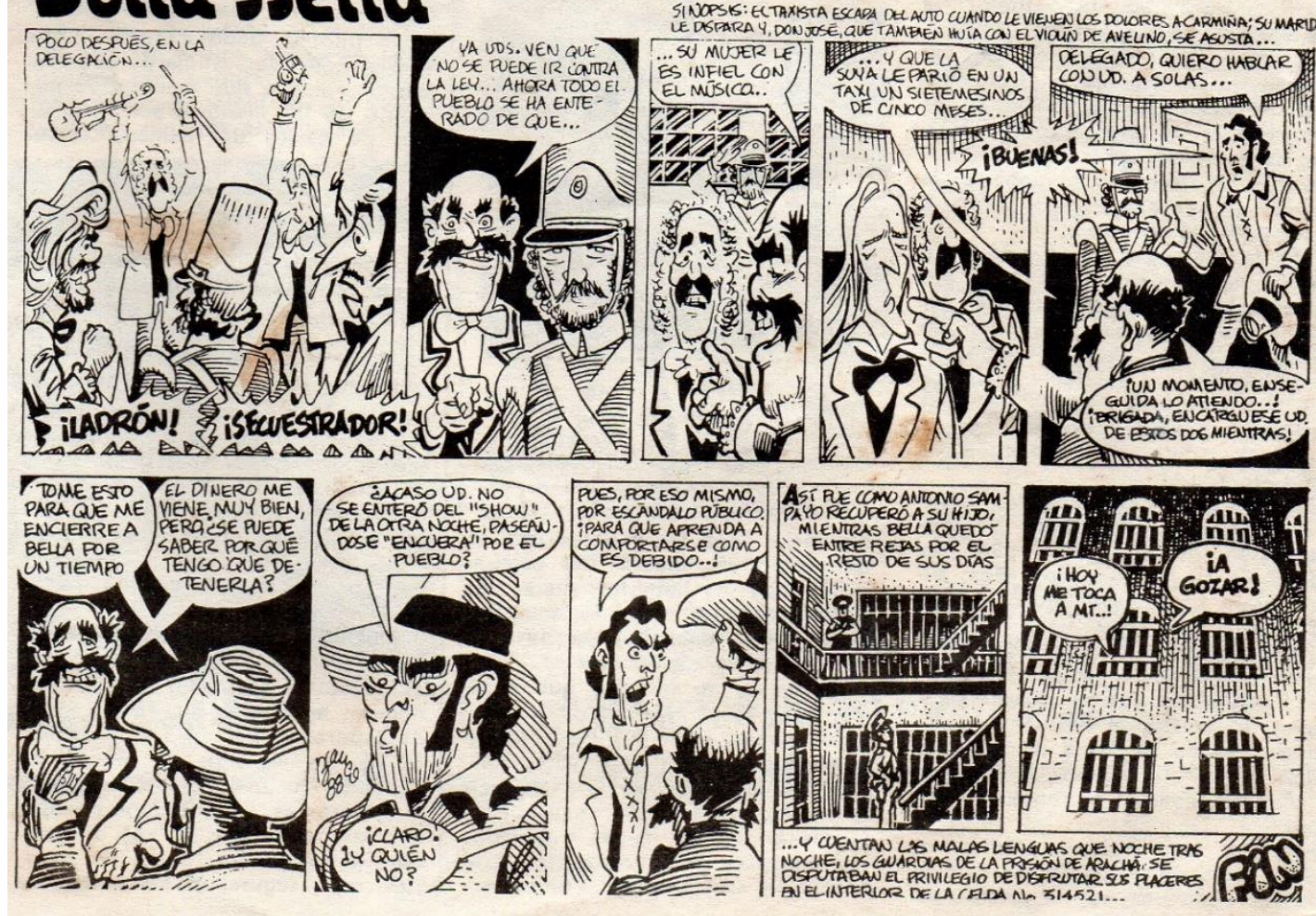

Fonte: Blanco, Francisco. Juventud Rebelde, 1988.

Tampouco foi feliz a comparação entre a adaptação em forma de quadrinhos e a versão radiofônica de Radio Rebelde; neste último caso, trata-se de uma sinopse, enquanto que a de Juventud Rebelde é uma paródia de pleno direito. Vejamos o que diz a respeito Lazar Kaprinarov, da Academia de Ciências Sociais da Bulgária: ... 
Para entender o cômico é necessária uma capacidade de sentimento que habitualmente chamamos de senso de humor, porque nem todas as pessoas estão capacitadas para entender o cômico e para possuir essa faculdade é necessário estar perto da vida, conhecê-la, e a enxergar em todas as suas riquezas e contradições (KAPRINAROV, 1982, p. 22)

Devo acrescentar que Juventud Rebelde recebeu não poucas cartas solicitando que se continuasse publicando a tira cômica diária, uma vez deixo de sair ao se limitar a programação de verão do jornal. Claro que não necessariamente a popularidade tem algo a ver com a realidade, mas tampouco tem que estar em disputa com ela.

Quanto à referência de "utilizar uma linguagem vulgar que na própria série não aparecia", também há bastante para se falar. Se algo distingue o nosso idioma é seu constante enriquecimento graças à imaginação popular, com seus valiosos acréscimos à língua mãe; do contrário, seria uma língua morta. $E$ isso se deve fundamentalmente à idiossincrasia de nossos povos latino-americanos com seu peculiar gracejo. Trate de interpretar o famoso personagem Inodoro Pereyra (Figura 9), do caricaturista Fontanarrosa, e verá que tem que recorrer a um dicionário de vocábulos gaúchos para poder entendê-lo em toda sua integralidade.

Figura 9 - Inodoro Pereyra, personagem criado pelo quadrinista argentino Fontanarrosa

\section{INODORO PEREYRA}

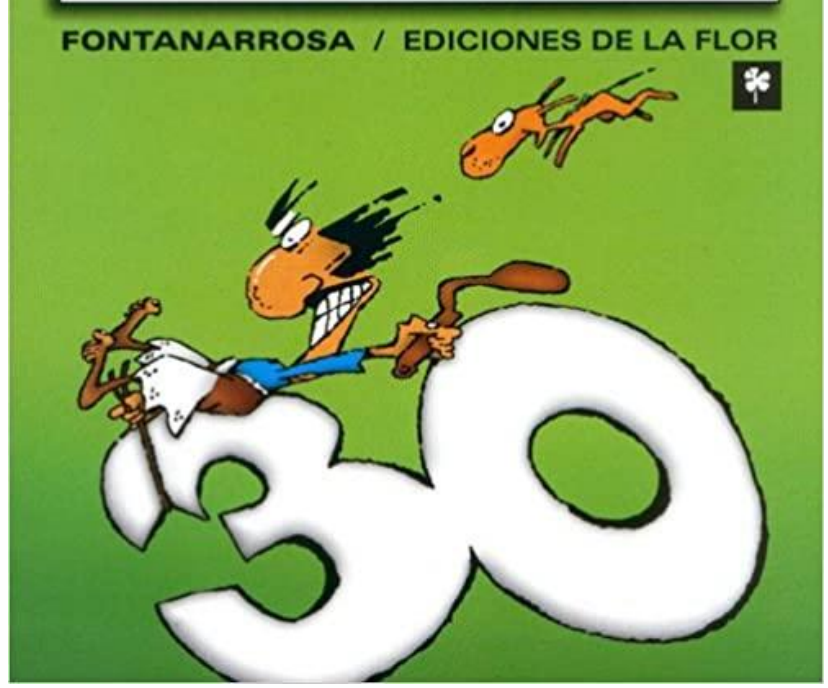

Fonte: https://www.amazon.com.br/Inodoro-Pereyra-30-Roberto-Fontanarrosa/dp/9505157746. Acesso em: 01 dez. 2021. 
De isso também se nutre o humor cubano e o considero muito mais sincero que a edulcoração linguística, quase vulgaridade da série brasileira, na qual a protagonista principal é qualificado do princípio ao fim com os adjetivos de rameira e cortesã, mas em nenhum momento se utilizam as palavras com que o povo identifica o "ofício" que pratica a Senhora de Arachá (sic) e que não têm nada de eufemismo. Podem ser localizadas nas páginas correspondentes ao P, no Pequeño Larousse Ilustrado (1968, p. 846).

Em minha opinião, tampouco se deve confundir a apreciação ou percepção artística com o direito de autor; é o próprio Koprinarov quem aborda o caráter co-recreativo da percepção da arte e sua percepção defeituosa, quando aclara:

Não só existem atores de talento, mas também espectadores de talento, Afirmação similar podem fazer tanto os pintores, como os compositores e qualquer artista em geral, porque todo artista conta com a participação do público. (KOPRINAROV, 1982, p. 56).

Indubitavelmente que é necessário que nossos intelectuais dediquem mais tempo à pesquisa científica da teoria da Arte. Seguiremos eternamente lamentando-nos da crise do humor em nosso país, ou vamos às raízes do problema? Até quando gostos pessoais vão ser elevados a categorias de verdades absolutas?

Coloquemos um último exemplo: no mesmo mês de dezembro, Luis Felipe Calvo, em El Caimán Barbudo, refere-se à pobre acolhida que deram os espectadores no [Teatro] Karl Marx ao espetáculo unipessoal do humorista argentino Leo Masliah ${ }^{3}$ (figura 10), enquanto em um quadro mais restrito os humoristas cubanos diziam que "A interpretação foi um verdadeiro presente, dado a novidade de seu afazer musical e a força satírica dos textos de suas canções" (CALVO, 1988).

\footnotetext{
${ }^{3}$ Nota do tradutor: Embora atuando profissionalmente na Argentina, Leo Masliah é originalmente uruguaio.
} 


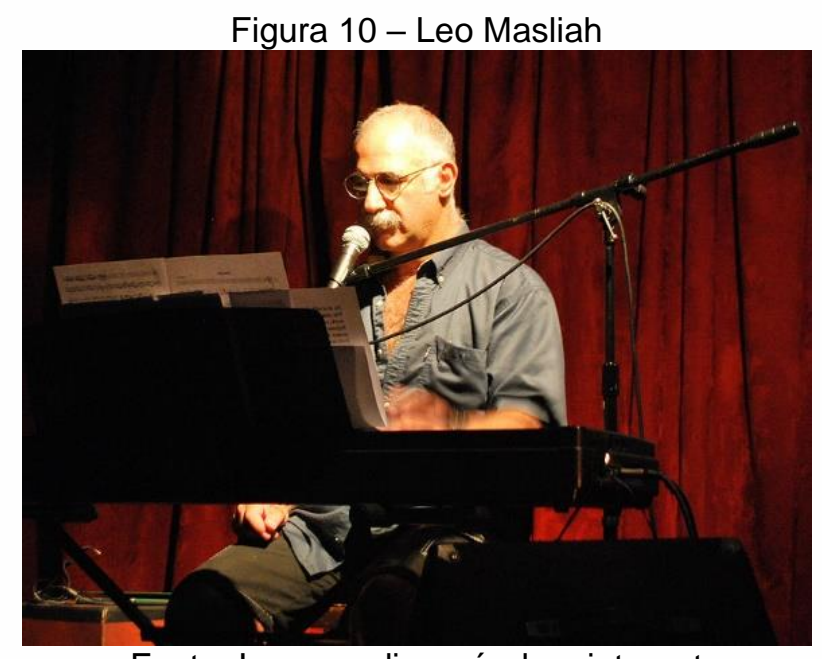

Fonte: Imagem disponível na internet

Foram igualmente paródias musicais as que popularizaram o Quinteto Rebelde na Sierra Maestra durante a insurreição armada, sirvam de exemplo o Yayabo Rebelde e Respeta al Che Guevara, esta última com letra de Santiago (Chago) Armada e música de Respeta tu amor.

O perigo da percepção defeituosa da obra de arte aumenta na medida em que essa incompreensão toma forma nos médios de difusão massiva, criando maior confusão no público.

Espera que essas opiniões - algumas minhas e outras de que me aproprio por similitude de opiniões -, ajudem a uma melhor compreensão da obra artística, e, sobretudo, dessa ovelha negra da família que é a paródia. Não importa que contra ela sigam-se utilizando termos tão fortes como - "falta de ética e de originalidade, abuso do direito de autor e facilismo" -, seguirei dedicando-lhe meus maiores esforços, e sempre sairei em sua defesa. Creio que nesta luta não ficarei sozinho.

\section{Referências}

CALVO, Luis Felipe. Ojos sin alas. El Caimán Barbudo, dic. 1988.

CARMONA, Margarita. El respecto al derecho ajeno. Mujeres, La Habana, p. 2021, dic. 1988.

CLIENTE morto não paga. Produção: David V. Picker, William E. McEuen. Direção: Carl Reiner. Intérpretes: Steve Martin, Carl Reiner, Cheryl Smith, Rachel Ward. Estados Unidos: 1988. 88m., Col., DVD. 
ECO, Umberto. Copiar a los grandes. El País, Madrid, n. 37, sábado, 05 nov. 1988.

KOPRINAROV, Lazar. Estética. La Habana: Editora Política, 1982.

NEM sangue, nem areia. Produção: Posa Filmes. Direção: Alejandro Galindo. Intérpretes: Cantinflas, Susana Guísar, Elvia Salcedo, Pedro Almendaríz, Alfredo del Diestro. México: 1941. 103m, Preto e Branco, DVD.

PEQUEÑO Larousse llustrado. La Habana: Instituto Cubano del Libro, 1968.

ROMEU e Julieta. Produção: Jacques Gelman, Santiago Reachi. Direção: Miguel M. Delgado. Intérpretes: Cantinflas, María Elena Marqués, Ángel Garasa, Andrés Soler, Emma Roldán, José Baviera. México: 1943. 100m, Preto e Branco, DVD.

SAINZ DE ROBLES, Federico Carlos. Diccionario de la literatura: términos, conceptos, ismos literários. Espanha: Aguilar, 1972.

OS TRÊS Mosqueteiros. Direção: Miguel M. Delgado. Intérpretes: Cantinflas, Ángel Garasa, Janet Alcoriza, Consuelo Franck, Andrés Soler. México: 1942. $139 \mathrm{~m}$, Preto e Branco, DVD. 